\title{
A Simplified Model for Parameter Estimation and Circuit Analysis of Inductive-Adder Modulator
}

\author{
W. Zhang, W. Eng, C. Pai, J. Sandberg, Y. Tan, Y. Tian \\ Presented at the IEEE International Power Modulator Conference 2006 \\ (2 $7^{\text {th }}$ International Power Modulator Symposium \& 2006 High Voltage Workshop) \\ Washington, D.C. \\ May $14-18,2006$
}

June 2006

\author{
XXX Collider-Accelerator Department XXX \\ Brookhaven National Laboratory \\ P.O. Box 5000 \\ Upton, NY 11973-5000 \\ www.bnl.gov
}

\begin{abstract}
Notice: This manuscript has been authored by employees of Brookhaven Science Associates, LLC under Contract No. DE-AC02-98CH10886 with the U.S. Department of Energy. The publisher by accepting the mamuscript for publication acknowledges that the United States Government retains a non-exclusive, paid-up, irrevocable, world-wide license to publish or reproduce the published form of this manuscript, or allow others to do so, for United States Government purposes.
\end{abstract}

This preprint is intended for publication in a journal or proceedings. Since changes may be made before publication, it may not be cited or reproduced without the author's permission. 


\section{DISCLAIMER}

This report was prepared as an account of work sponsored by an agency of the United States Government. Neither the United States Government nor any agency thereof, nor any of their employees, nor any of their contractors, subcontractors, or their employees, makes any warranty, express or implied, or assumes any legal liability or responsibility for the accuracy, completeness, or any third party's use or the results of such use of any information, apparatus, product, or process disclosed, or represents that its use would not infringe privately owned rights. Reference herein to any specific commercial product, process, or service by trade name, trademark, manufacturer, or otherwise, does not necessarily constitute or imply its endorsement, recommendation, or favoring by the United States Government or any agency thereof or its contractors or subcontractors. The views and opinions of authors expressed herein do not necessarily state or reflect those of the United States Government or any agency thereof. 


\title{
A Simplified Model for Parameter Estimation and Circuit Analysis of Inductive-Adder Modulator*
}

\author{
W. Zhang, W. Eng, C. Pai, J. Sandberg, Y. Tan, Y. Tian \\ Brookhaven National Laboratory \\ Upton, NY 11973
}

\begin{abstract}
In this paper, we propose a simplified model for easy estimation of design parameters and quick analysis of inductive adder modulators. Analytical method is used to deduct the simplified circuit model. This model offers an easy way to understand the behavior of the inductive-adder modulator circuits and provides designers a helpful tool to estimate critical parameters such as pulse rise time, system impedance, number of adder stages, etc. Computer simulations demonstrate that parameter estimation based on simplified circuit model is fairly accurate as compared to original circuit. Further more, this approach can be used in early stage of system development to assist the feasibility study of the project and to aid geometry selection and parameter selection of critical components.
\end{abstract}

\section{INTRODUCTION}

The demonstration of ARM-II solid-state modulator at LLNL in 1998 opened a new era in pulsed power modulator technology [1]-[3]. This modulator was based on induction voltage adder (IVA) topology. Other systems built on the same principle such as DARHT-II kicker modulator and the prototype AHF kicker modulator further revealed the amazing capabilities of this new technology. Scientists and engineers elsewhere are eager to try to expand this modulator topology to other applications.

However, there is very little literature to help people to understand the parameter range and feasibilities of induction adder modulator in design and development process. During our effort to build a solid-state induction adder modulator, we frequently encountered inquiries of achievable parameters of multi-stack modulator. Primary inquires are voltage or current amplitude, pulse rise time and fall time, pulse duration range, pulse repetition rate, and ability to generate arbitrary pulse waveforms.

In [4] and [5] a single cell circuit model of IVA was given as in Fig. 1. Where, SW is the main switch, $\mathrm{C}_{\mathrm{S}}$ is the capacitance of energy storage capacitor, $\mathrm{R}$ is the parallel resistor, $\mathrm{L}_{\mathrm{K}}$ is core leakage inductance, $\mathrm{L}_{\mathrm{P}}$ is primary core inductance, and $L_{1}$ and $C_{1}$ are the distributed inductance and capacitance of stalk per stack section length.

When the main switch SW is closed, the state space description of single cell circuit is shown in Fig. 2.

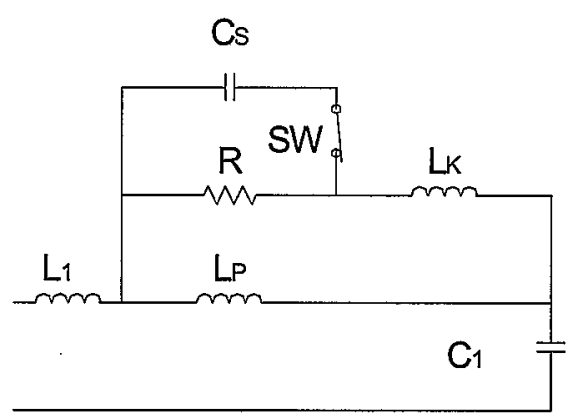

Fig. 1. A single cell model of inductive voltage adder.

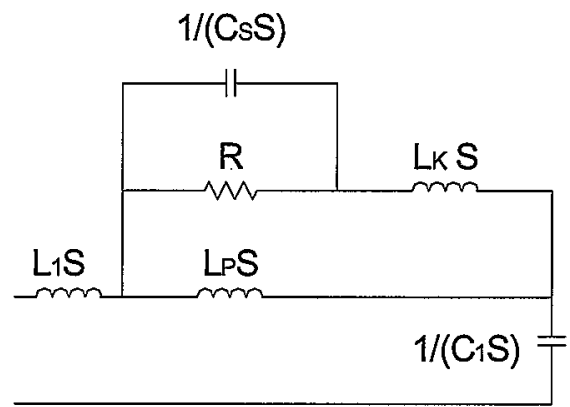

Fig. 2. State space description of a single cell model of inductive voltage adder with switch closed.

\section{THE OUTPUT IMPEDANCE AND TRANSMISSION DELAY TIME ESTIMATIONS}

Traditionally, the output impedance has been treated as the stalk impedance [4]-[5]. This condition is true, if transformer primary inductance and leakage inductance are negligible. However, in fast pulse circuit they have to be considered in the design. Reference [5] showed an interesting case of output mismatch to stalk impedance. To analyze output impedance, we use zero-state analysis.

Let us define $Z_{1}$ to be the impedance of storage capacitor $C_{S}$ in parallel of $R$, and $Z_{2}$ to be the summation of $Z_{1}$ and leakage inductance $\mathrm{L}_{\mathrm{k}}$. Then, we have the following equations 


$$
\begin{aligned}
& Z_{1}=R / / \frac{1}{C_{S} S} \\
& =\frac{R}{R C_{S} S+1}
\end{aligned}
$$

and

$$
\begin{aligned}
& Z_{2}=Z_{1}+L_{K} S \\
& =\frac{R+L_{K} S+R C_{S} L_{K} S^{2}}{R C_{S} S+1}
\end{aligned}
$$

If we define $Z_{3}$ as the impedance of $Z_{2}$ in parallel with primary inductance $L_{P}$, we have

$Z_{3}=Z_{2} / / L_{P} S$

$$
\begin{aligned}
& =\frac{1}{\frac{1}{Z_{2}}+\frac{1}{L_{P} S}} \\
& =\frac{\left(R+L_{K} S+R C_{S} L_{K} S^{2}\right) L_{P} S}{R+\left(L_{K}+L_{P} R\right) S+\left(L_{P} L_{K}+R C_{S} L_{K}\right) S^{2}+R C_{S} L_{P} L_{K} S^{3}}
\end{aligned}
$$

Further, if $Z_{4}$ is defined as the summation of $Z_{3}$ and sectional stalk inductance $L_{1}$, we can deduct it as

$$
\begin{aligned}
& Z_{4}=Z_{3}+L_{1} S \\
& =\frac{\left(R+L_{K} S+R C_{S} L_{K} S^{2}\right) L_{P} S}{R+\left(L_{K}+L_{P} R\right) S+\left(L_{P} L_{K}+R C_{S} L_{K}\right) S^{2}+R C_{S} L_{P} L_{K} S^{3}}+L_{1} S
\end{aligned}
$$

Consider that the capacitance of storage capacitor has to be large in order to keep voltage constant and be able to provide high repetition rate pulse burst without recharge. In addition, the frequency spectrum of the pulse is usually in the high frequency band for pulsed power or pulsed $\mathrm{RF}$ applications. The impedance of $\mathrm{C}_{S}$ at the high frequency range is much larger than the parallel resistor $R$, and hence $R$ can be ignored. Therefore, we have the following approximation. If $C_{S} S \gg \frac{1}{R}$, then

$Z_{1}=R / / \frac{1}{C_{S} S}$.

$$
\approx \frac{1}{C_{S} S}
$$

Redraw the single cell circuit model in Fig. 2 with resistor $\mathrm{R}$ eliminated, it becomes the circuit shown in Fig. 3.

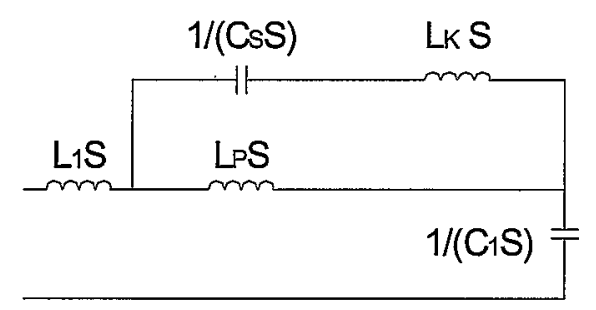

Fig. 3. A single cell model with $\mathrm{R}$ eliminated.

Apply (5) into (2) and (3), we have

$$
\begin{aligned}
& Z_{2}=Z_{1}+L_{K} S \\
& \approx \frac{1}{C_{S} S}+L_{K} S \\
& =\frac{1+C_{S} L_{K} S^{2}}{C_{S} S}
\end{aligned}
$$

and

$$
\begin{aligned}
& Z_{3}=Z_{2} / / L_{P} S \\
& \approx \frac{1}{\frac{1+C_{S} L_{K} S^{2}}{C_{S} S}+\frac{1}{L_{P} S}} \\
& =\frac{L_{P} S\left(1+L_{K} C_{S} S^{2}\right)}{1+\left(L_{K}+L_{P}\right) C_{S} S^{2}}
\end{aligned}
$$

Another fact is that the leakage inductance has to be very low comparing to the primary inductance for an efficiently coupled core design. Therefore, if $L_{K} \cdot<L_{P}$, then

$$
Z_{3} \approx \frac{L_{P} S\left(1+L_{K} C_{S} S^{2}\right)}{1+L_{P} C_{S} S^{2}}
$$

At high frequency range the parameters can be chosen to satisfy $L_{K} C_{S} S^{2} \gg 1$ and $L_{P} C_{S} S^{2} \gg 1$. Then the impedance parameters $Z_{3}$ and $Z 4$ can be simplified as following

$Z_{3} \approx \frac{L_{P} S\left(L_{K} C_{S} S^{2}\right)}{L_{P} C_{S} S^{2}}$

$=L_{K} S$

and

$Z_{4}=Z_{3}+L_{1}$

$\approx L_{K} S+L_{1} S$

$=\left(L_{K}+L_{1}\right) S$

The circuit in Fig. 3 is reduced to the one shown in Fig. 4.

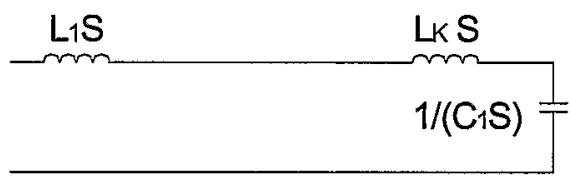

Fig. 4. A simplified single cell model.

The output impedance is

$$
Z=\sqrt{\frac{L_{K}+L_{1}}{C_{1}}}
$$

This result shows that the circuit output impedance is larger than the stalk impedance due to the contribution of the leakage inductance. In order to minimize pulse reflections, the output cable and load shall match to the circuit output impedance $\mathbf{Z}$ rather then the stalk impedance.

Based on the result of Fig. 4 and (11), an N-stack induction voltage adder is reduced to an $\mathrm{N}$-section transmission line as shown in Fig. 5.

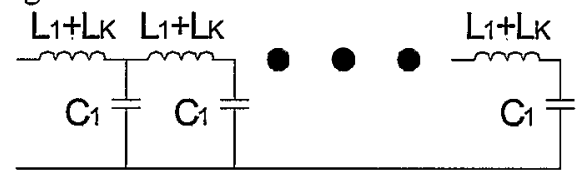

Fig. 5. A simplified inductive adder model. 
The impedance of this $\mathrm{N}$-section transmission line is $\mathrm{Z}$ as given in (11).

\section{ESTIMATION ACCURACY AND EXAMPLE OF OUTPUT IMPEDANCE}

To demonstrate the matching effect of output impedance and stalk impedance we use an example. Note that in the following example the stalk is shorted at left end and a matching load resistor is connected to the right end.

\section{A. Example 1}

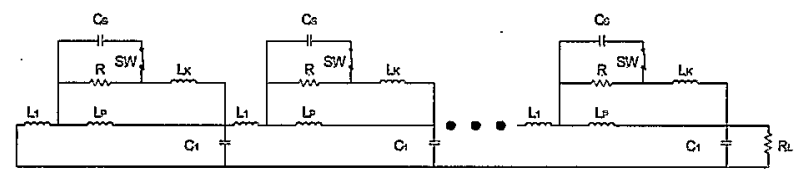

Fig. 6. A single ended multi-stack inductive adder.

In this example, we investigate the circuit given in [5] a 30stalk inductive voltage adder. Its parameters are listed in TABLE I.

TABLE I

SIMULATION PARAMETERS

\begin{tabular}{|c|c|c|}
\hline Symbol & Parameter & Quantity \\
\hline $\mathrm{C}_{\mathrm{S}}$ & storage capacitance & $24 \times 10^{-6} \mathrm{~F}$ \\
\hline$L_{P}$ & primary inductance & $20.9 \times 10^{-6} \mathrm{H}$ \\
\hline$L_{K}$ & leakage inductance & $6.5 \times 10^{-9} \mathrm{H}$ \\
\hline$L_{I}$ & stalk inductance per stake & $20 \times 10^{-9} \mathrm{H}$ \\
\hline$C_{l}$ & stalk capacitance & $2.6 \times 10^{-12} \mathrm{~F}$ \\
\hline $\mathrm{N}$ & number of stakes & 30 \\
\hline $\mathrm{V}_{0}$ & initial voltage of $C_{S}$ & $1000 \mathrm{~V}$ \\
\hline$R$ & parallel resistance & 50 \\
\hline$Z_{\text {STALK }}$ & stalk impedance & 50 \\
\hline
\end{tabular}

The simulation circuit is shown in Fig. 7.
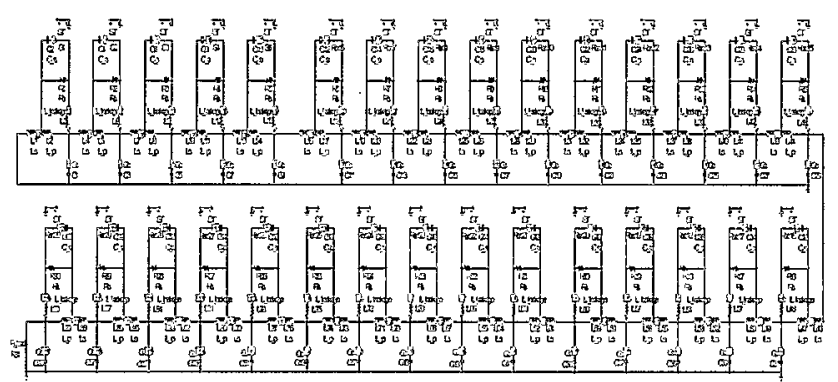

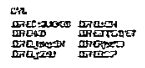

Fig. 7. A 30-stack inductive adder simulation circuit.

Using the impedance estimation formula given in (11) and parameters in Table 1, we have

$Z=\sqrt{\frac{(20+6.5) e^{-9}}{2.6 e^{-12}}}=100.96 \Omega$

Here we use a $100 \Omega$ load resistor that is close enough to the estimation impedance in the first simulation.

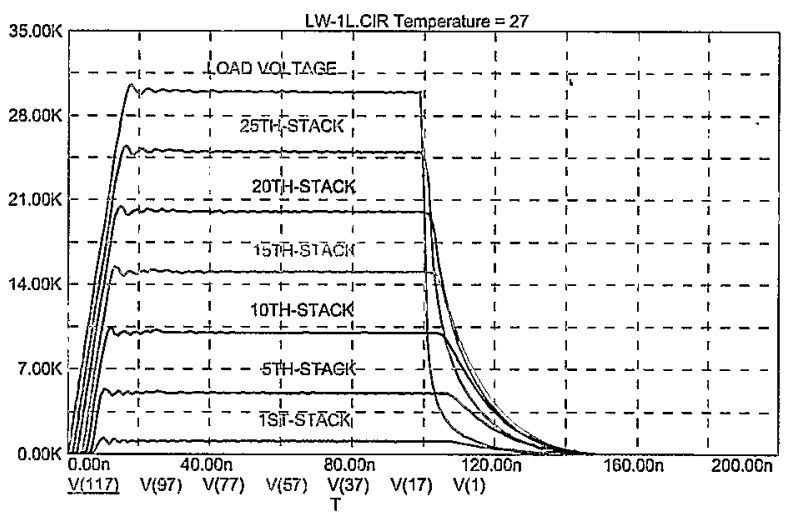

Fig. 8. Voltage pulse waveforms with $100 \Omega$ load impedance.

As a comparison, we used a $50 \Omega$ load resistor that equals the impedance of the stalk in the second case.

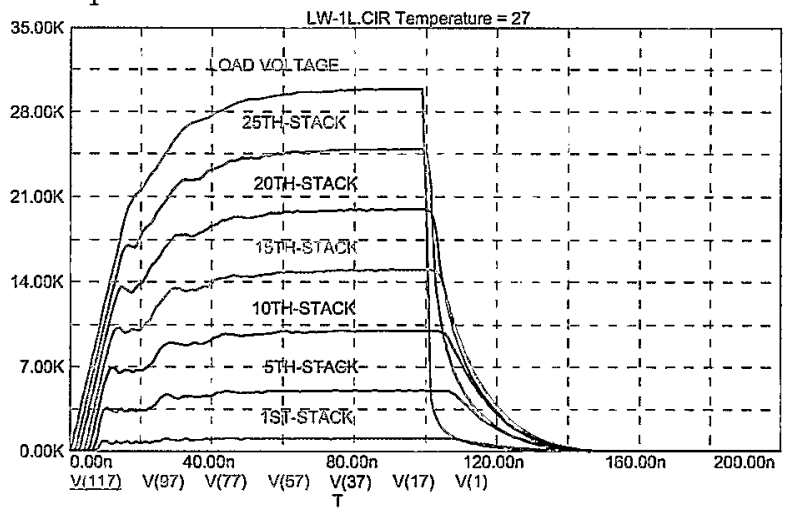

Fig. 9. Voltage pulse waveforms with $50 \Omega$ load impedance. 10.

The comparison of two simulation results is given in Fig.

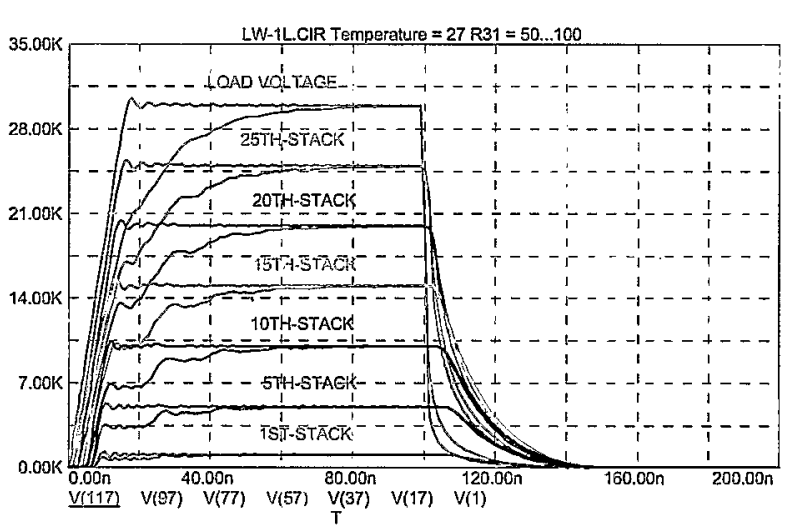

Fig. 10. Comparison of voltage pulse waveforms with $100 \Omega$ and 50 Sload impedances.

It is easy to see that using impedance estimation formula given in this paper produces a clean and sharp pulse waveform at load. This result also validates the merit to reduce stalk impedance [5] in order to match pre-specified load impedance of $50 \Omega$. 


\section{B. Accuracy of estimation}

To evaluate the accuracy of the estimation, we wrote a short script in MATLAB ${ }^{\circledR}$. This script calculates the output impedance of the stalk based on its actual parameters and the estimated output impedance using simplified method at each frequency of interest.

In Fig. 11, the blue trace is the output impedance of the circuit with actual parameters and the red trace is the estimated output impedance using formula in (11).

One can see that over the frequency range of pulse operation, the estimated parameter based on simplified method matches well with the actual output impedance.

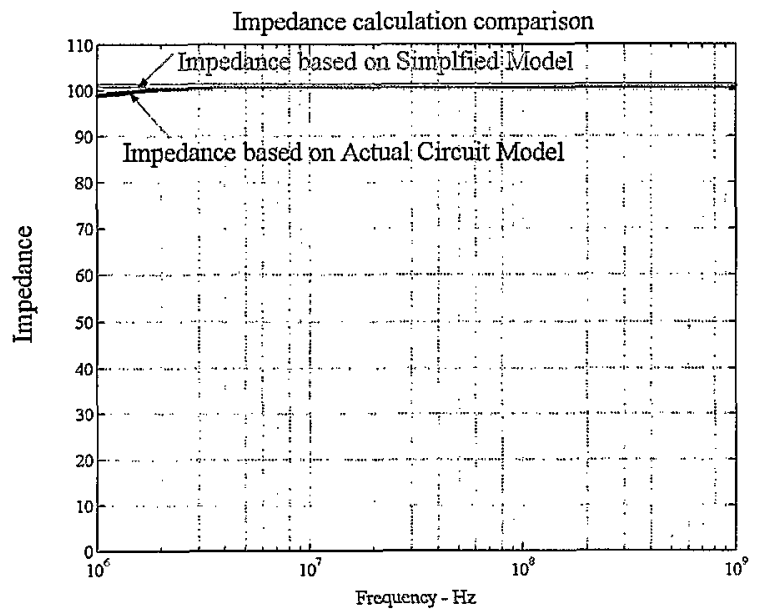

Fig. 11. Comparison of impedance calculation based on actual or simplified circuit model.

\section{ESTIMATION OF PULLE RISE TIME}

The output pulse is generated by slightly discharging large storage capacitors of stakes. Each stack cell has a natural resonant frequency of

$\omega_{o}=\frac{1}{\sqrt{\left(L_{1}+L_{K}\right) C_{1}}}$

and a one-way propagation time as well as the pulse response time of

$T_{C}=\sqrt{\left(L_{1}+L_{K}\right) C_{1}}$.

The pulses produced by each stack will travel bidirectionally and add up at load. If the inductive voltage adder is terminated at both ends with matched impedance loads, then the pulse rise time of each output pulse is

$T_{R D}=N \sqrt{\left(L_{K}+L_{1}\right) C_{1}}$.

A single ended inductive adder with matched impedance load and a short at the far end will have a rise time of $T_{R}=2 N \sqrt{\left(L_{K}+L_{1}\right) C_{1}}$.

\section{A. An example of pulse rise time estimation}

An example can be given. Using parameters given in TABLE I, we have that the output pulse rise time is

$$
T_{R}=2 \times 30 \sqrt{(20+6.5) e^{-9} \times 2.6 e^{-12}}=16.9 n S
$$

We performed a computer simulation of the circuit used in Example 1, and its load voltage pulse rising edge verses time is shown in Fig. 12. The pulse rise time of other stacks are also shown for illustration. Here, all switches are assumed to be ideal and closed simultaneously at 1 nano-second from time zero of simulation.

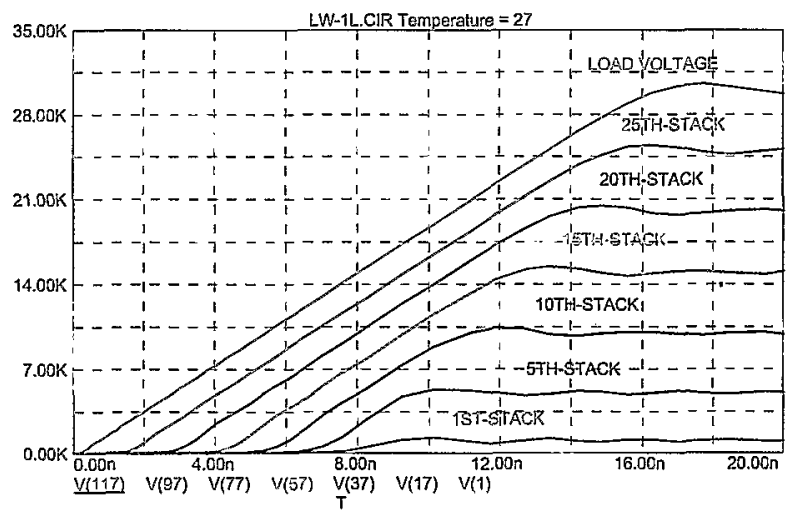

Fig. 12. Voltage pulse rising edge.

The result of load voltage rise time shown in Fig. 12 agrees with the calculation.

\section{CONCLUSION}

The parameter estimation methods based on simplified circuit models presented in this paper are accurate and easy to use. As inductive voltage adder technology becomes popular, the design tools will be needed to help design and development process. In addition, a simplified model and estimation method will illustrate the design concept to customers in a clear form.

\section{REFERENCES}

[1] L. Reginato, et al., "Pulsed Ferrite Core Tests for 50-ns Linear Induction Accelerator", IEEE Trans. Magn., vol. 14, pp. 972-974.

[2] Kirbie, $\mathrm{H}$., et al., "An all solid state pulse power source for high PRF induction accelerators", Conference Record of the 1998 Twenty-Third International Power Modulator Conference, 22-25 June 1998, pp. 6-11.

[3] Kirbie, H., et al., "MHz repetition rate solid-state driver for high current induction accelerators", Proceedings of the 1999 Particle Accelerator Conference, vol. 1, 27 March-2 April 1999, pp. 625 - 627.

[4] L. Wang, et al., "Modeling of an Inductive Adder Kicker Pulser for a Proton Radiography System", Digest of Technical Papers, Pulsed Power Plasma Science, 2001. PPPS-2001. vol. 2, 17-22 June 2001, pp. 15791582.

[5] L. Wang, et al., "Modeling of an Inductive Adder Kicker Pulser for DARHT-II", Proceedings of the 20th International LINAC Conference, 2000, pp. 509-511. 